\title{
Escolha da especialização em Ginecologia e Obstetrícia
}

\author{
Choice of specialization in $\mathrm{Ob}$ Gyn
}

A especialização faz parte da identificação profissional do médico e tem raízes anteriores à graduação em Medicina. Existem muitas influências na escolha da área de especialização, que incluem diferenças individuais em aptidões, habilidades e personalidade, circunstâncias que antecedem ou decorrem do treinamento clínico, bem como injunções das perspectivas de inserção profissional, tanto oportunidades e recompensas, como desgastes e frustrações.

A escola médica desempenha papel relevante nessa escolha, na confirmação ou substituição da preferência inicial por uma dada especialidade. Essa influência se apresenta em múltiplos aspectos, tais como currículo, recursos humanos, cenários de ensino, formas em que as disciplinas estão estruturadas, adequação da supervisão pelos preceptores, etc., que incidem principal, mas não exclusivamente, durante o internato médico ${ }^{1}$.

$\mathrm{Na}$ área de Ginecologia e Obstetrícia (GO), apesar de poucos estudos publicados enfocando fatores que definem a preferência por essa especialidade médica em detrimento de outras, observou-se que a satisfação com o treinamento em serviço foi uma influência consistente ${ }^{2,3}$, e que há uma crescente predominância de mulheres entre os candidatos a essa especialidade no exterior ${ }^{4}$ - aspecto esse que não foi encontrado em estudo realizado na década passada no Brasil ${ }^{5}$. Trabalho realizado nos Estados Unidos observou que sexo, etnia e experiência satisfatória no treinamento clínico foram fatores preditivos estáveis na escolha por GO na última década, enquanto outros sofreram variações conforme diferentes circunstâncias ${ }^{3}$.

Estudo realizado com 792 graduandos da Faculdade de Medicina da Universidade de Brasília (UnB), no período de 1994 a 2006, não mostrou diferença significativa na inscrição para Residência Médica em GO entre os sexos (6,4\% de homens versus $9,9 \%$ de mulheres; $\mathrm{p}=0,07)$. No entanto, a realização de monitorias e estágio optativo em GO e o nível de rendimento acadêmico, tanto global como na área em questão, demonstraram forte associação com a futura escolha da especialização. Interessante observar que 8\% (63) dos 792 estudantes escolheram GO como especialidade médica - proporção significativamente maior que os $5,2 \%$ que indicaram preferência por essa área logo que ingressaram no curso ( $\mathrm{p}=0,01$; teste de McNemar) ${ }^{6}$.

Cinco características são apontadas como necessárias para o bom ginecologista-obstetra: gostar de trabalhar com as mãos e de cuidar de mulheres, apreciar resultados imediatos dos seus esforços, saber lidar com assuntos delicados em situações tensas e tomar decisões rápidas com autoconfiança ${ }^{7}$. Nessa perspectiva, o internato parece constituir a ocasião decisiva para

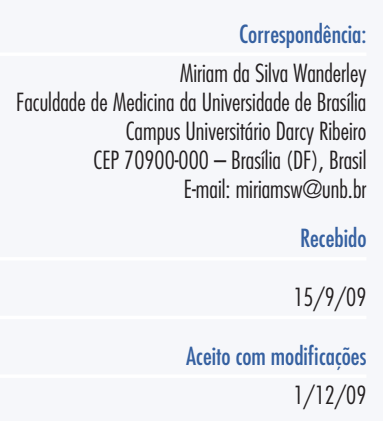

I Professora Adjunto de Ginecologia e Obstetrícia da Faculdade de Medicina da Universidade de Brasília - UnB - Brasília (DF). Brasil.

2 Professor Emérito da Faculdade de Medicina da Universidade de Brasília - UnB - Brasília (DF), Brasil. 
o estudante confirmar ou não a sua compatibilidade com a área, reconhecendo possuir ou não as habilidades adequadas para segui-la. No estudo da UnB, quase $10 \%$ dos egressos mudaram de preferência no tocante a GO do início ao término do curso. E, destes, $40 \%$ se inscreveram em Residências Médicas denominadas - na falta de um termo melhor - com estilo de vida "governável", tais como Anestesiologia, Dermatologia, Oftalmologia, Otorrinolaringologia e Radiologia ${ }^{6}$; observação essa que, por si só, já ensejaria posterior estudo mais aprofundado.

Novos aspectos emergem quando se analisa a obtenção do título de Especialista em Ginecologia e Obstetrícia (TEGO) pelos egressos da UnB. Trabalho recente mostrou que a medida de interesse pela área durante a graduação foi importante para a escolha da especialidade, mas não se traduziu em aprovação no TEGO ( $\mathrm{p}=0,7)$. Paralelamente, os índices de rendimento global no curso e nas disciplinas de GO mostraram correlações significantes com a obtenção do título. Além disso, a proporção de obtenção do título foi maior entre participantes do sexo feminino $(55,2$ versus $38,1 \%)$ e com menos de 26 anos, associação claramente relacionada ao menor intervalo de tempo entre a Residência Médica e a prova e obtenção do TEGO ${ }^{8}$.

No trabalho citado, não se observou diferença significativa entre os participantes com ou sem TEGO e a menção no internato em GO, que expressa de forma mais clara o desempenho prático em serviço ${ }^{8}$. Por outro lado, a relação com o rendimento acadêmico sugere que a busca pela obtenção do TEGO está correlacionada a um maior engajamento em atividades de educação continuada e aptidão para o estudo ${ }^{8,9}$.

Apesar das limitações, o TEGO se constitui como critério válido tanto para a certificação e o estímulo à educação continuada na especialidade, como para a própria atuação profissional. Trabalho recente observou que a maioria das denúncias no Conselho Regional de Medicina do Estado de São Paulo (CREMESP) relativas ao exercício da GO ocorreu com médicos que não possuíam o TEGO ${ }^{10}$.

Ressalte-se novamente a importância da escola médica e dos serviços de Residência Médica no estímulo ao constante aprimoramento do aprendiz. Esse papel, aliás, que as Sociedades de Ginecologia e Obstetrícia e a FEBRASGO não podem se furtar em exercer junto ao médico especialista. Na sociedade globalizada, em que as informações são mais acessíveis, mas nem sempre embasadas cientificamente, é fundamental que o médico se mantenha atualizado e preserve a adequada relação médico-paciente que deve ter aprendido durante a sua graduação.

Conclui-se por sugerir que essa trajetória de identificação profissional importa pessoalmente a qualquer especialista, tem impacto expressivo no trabalho médico e repercussão apreciável no atendimento à população. Os estudos referidos ilustram aspectos significativos desse processo.

\section{Referências}

1. Ellsbury KE, Carline JD, Irby DM, Stritter FT. Influence of third-year clerkship on medical student specialty preferences. Adv Health Sci Educ Theory Pract. 1998;3(3):177-86.

2. Hammond MM, Stansfield RB, Katz NT, Dugoff L, McCarthy J, White CB. The effect of the obstetrics and gynecology clerkship on students' interest in a career in obstetrics and gynecology. Am J Obstet Gynecol. 2006; 195(5): 1422-6.

3. McAlister RP, Andriole DA, Rowland PA, Jeffe DB. Have predictors of obstetrics and gynecology career choice among contemporary US medical graduates changed over time? Am J Obstet Gynecol. 2007; 196(3):275.e1-7.

4. Turner G, Lambert TW, Goldacre M, Barlow D. Career choices for obstetrics and gynaecology: national surveys of graduates of $1974-2002$ from UK medical schools. BJOG. 2006;113(3):350-6.

5. Figueiredo JF, Rodrigues ML, Troncon LE, Cianflone AR. Influence of gender on specialty choices in a Brazilian medical school. Acad Med. 1997;72(1):68-70.

6. Sobral DT, Wanderley MS. Escolha de ginecologia e obstetrícia por graduandos da Universidade de Brasília: um estudo de influências numa série histórica. Rev Bras Educ Méd. 2008;32(4):452-61.

7. Freeman B. The ultimate guide to choosing a specialty. 2nd ed. New Delhi: McGraw-Hill; 2007.

8. Wanderley MS, Sobral DT. Certificação de especialização em ginecologia e obstetrícia por egressos da Universidade de Brasília [Internet]. Brasília Med. 2009; 46(1):29-35 [citado 2009 Ago 20]. Disponível em: http://www.ambr.com.br/rb/arquivos/07_bsb_med_46(1)_art_ orig_certificacao_ginecologia.pdf

9. Spellacy WN. The OB/GYN clerkship rotation sequence. Does it affect performance on final examinations? J Reprod Med. 1998;43(2):141-3.

10. Boyaciyan K, Camano L. O perfil dos médicos denunciados que exercem ginecologia e obstetrícia no estado de São Paulo. Rev Assoc Med Bras. 2006;52(3): 144-7. 